\title{
Endoscopic Vacuum Therapy for Die-Hard Leaks After Esophagectomy in Multiple Comorbid Esophageal Cancer Patients
}

\author{
II Hyun Baek ${ }^{1}$, Seong Hwan Kim²
}

Corresponding author:

II Hyun Baek, M.D., Ph D, Department of Gastroenterology

Eulji University Hospital Eulji University School of Medicine 1306, Dunsan-dong, Seo-gu, Daejeon, Rep. of KOREA 35233

E-mail: drandrea100@daum.net

\author{
'Department of Gastroenterology, Eulji University Hospital, Eulji University School of Medicine, \\ Daejeon, Korea \\ ${ }^{2}$ Department of Gastroenterology, Eulji General Hospital, Eulji University School of Medicine, \\ Seoul, Korea
}

\section{ABSTRACT}

Postoperative leakage of upper gastrointestinal tract secondary to esophagectomy or gastrectomy is considered a dangerous situation due to the possible occurrence of mediastinitis and following sepsis. We experienced two multiple comorbid cases of luminal wall defect developed after esophageal resection for squamous cell carcinoma of the esophagus. The patients were treated by jejunostomy and prolonged parenteral nutrition, but the defects persisted. To resolve the defect lesion, we used continuous suction with endoscopically applied a vacuum-sealed size-adjusted polyurethane vacuum system (Endoscopic Vacuum Therapy; EVT). EVT was performed as an isolated therapy or as a combination therapy with fibrin glue for the acceleration of healing. Without any procedure-related complications, both patients' leaks were resolved. Complete closure was verified by esophagogastroduodenoscopy and upper gastrointestinal tract series. Endoscopic vacuum assisted closure using a sponge can be an appropriate new therapeutic selection for wall defect after upper gastrointestinal surgery, especially in multiple comorbid patients.

Key words: Endoscopic Vacuum Therapy (EVT), esophagectomy, wall defect

\section{INTRODUCTION}

Esophageal or gastric leakage after esophagectomy or gastrectomy has been reported in approximately $7 \%$ to $20 \%$ of cases and can cause critical conditions due to mediastinitis and consecutive systemic sepsis $(1,2)$. Endoscopic treatments such as endoscopic suturing, metal clip application, over-the-scope clips (OTSC) and injection of fibrin glue, can be effectively used as an alternative to surgical treatment for small defects without tissue perfusion impairment or sepsis $(3,4)$. At the present time, when the patient is in a non-septic condition, the disposition of self-expanding partially or fully covered plastic or metal stents (SEPS or SEMS) is the first treatment in esophageal perforations or anastomotic leakages (5-7). This endoscopic stenting is of benefit to evading the significant 
risk of emergency operation such as two-stage esophageal reconstruction with discontinuity resection and cervical esophagostomy. But, stent treatment may go in company with topical pressure necrosis of the esophagus, adscititious abscess drainage, imperfect defect closure resulting from stent migration, persistent leakage or the subsequent failure of stent removal by growth into the stent. In addition, the success rate after endoscopic stent treatment varies greatly (8).

Recently, endoscopic vacuum therapy (EVT) has shown good results in various perforations and leaks of upper gastrointestinal tract (9-11). This vacuumassisted closure technique stands on the basis of the negative pressure on wall defects through a vacuumsealed sponge $(12,13)$. This negative pressure causes reduction of local edema, secretion, bacterial contamination and acceleration of granulation and perfusion. By inserting a polyurethane sponge into the defect area with an endoscope and then transnasally applying external vacuum, efficacious drainage and defect closure are achieved.

We would like to report the treatment experience of EVT in esophageal cancer patients with various comorbidities who failed to heal despite surgery and conservative treatment for wall defect developed after esophagectomy.

\section{CASE PRESENTATION}

\section{Case 1}

A 67-year-old male patient complaining of dysphagia was diagnosed with esophageal squamous cell carcinoma from the upper incisor 26 to $29 \mathrm{~cm}$ on endoscopy. The patient underwent endoscopic submucosal dissection (ESD) for esophageal cancer. During the procedure, small esophageal perforation was developed. The patient received emergent Ivor-Lewis operation. Four years after the surgery, he received a left lower lung lobectomy for squamous cell lung cancer. Two years after lung lobectomy, he received an emergent gastric primary repair operation for ulcer perforation. Fourteen days after primary repair operation, gastric ulcer perforation was developed again. He received a second emergent gastric primary repair operation. At 35 days after second repair surgery, bile colored fluid was still drained through the chest tube. So, feeding jejunostomy was performed. Even prolonged parenteral nutrition for two months after jejunostomy, bile colored fluid was still drained through the chest tube. EVT was initiated because a wall defect was found in the intra- thoracic stomach on esophagogastroduodenoscopy (EGD). First, we cut open-pored polyurethane sponge (CuraVAC; Daewoong Pharma, Seoul, Korea) to a suitable size and attached it to the end of the nasogastric tube. The tube was retrieved through the mouth after inserting into the nose. Using grasper forceps, the tube was inserted, and the sponge was intra-luminally was placed in the appropriate area of the wall defect. The tube was linked to a portable suction system after retrieval of the EGD. A negative pressure of $120 \mathrm{~mm} \mathrm{Hg}$ was sustained persistingly during therapy. The positioning of the sponge was confirmed endoscopically. From the second procedure, to accelerate closure of the opening, we submucosally injected $6 \mathrm{~mL}$ fibrin glue (Greenplast $Q$ prefilled syringe kit $2 \mathrm{~mL}$; PFS. 1 : human fibrinogen concentrate $95 \mathrm{mg}$ aprotinin 1000KIU, PFS. 2 : thrombin 500IU, Green Cross Corp, Seoul, Korea) through an injection catheter, followed by sponge placement, This concurrent fibrin injection was repeated at every sponge exchange. Without any procedurerelated complications, the sponge was replaced three times in 3 to 14 days intervals for 22 days. At 43 days after the initial procedure, complete closure was confirmed by esophagography (fig. 1).

\section{Case 2}

A 73-year-old man presented soreness and dyspepsia. He was diagnosed with lower esophageal squamous cell carcinoma on endoscopy. Thirty years ago, he received cystojejunostomy due to pancreatic pseudocyst. Ten years ago, he received small bowel resection and distal pancreatectomy due to intestinal obstruction by tuberculosis. The patient received Ivor-Lewis operation and gastric wedge resection due to severe adhesion between gastric midbody posterior wall and resected distal pancreas. Seven days after surgery, severe abdominal pain was suddenly developed. Serous and bloody fluid was drained through the chest tube and feeding jejunostomy. Emergent segmental bowel resection for jejunal perforation with bleeding \& feeding jejunostomy reinsertion was performed. At 27 days, turbid and serous fluid was still drained through the chest tube. In EGD, a wall defect was found near the anastomotic margin. Therefore, EVT was initiated as previously mentioned method. Without any procedure-related complications, the sponge was replaced five times in 11 to 16 days intervals for 56 days. At 81 days after the initial procedure, complete closure was confirmed by esophagography (fig. 2). 


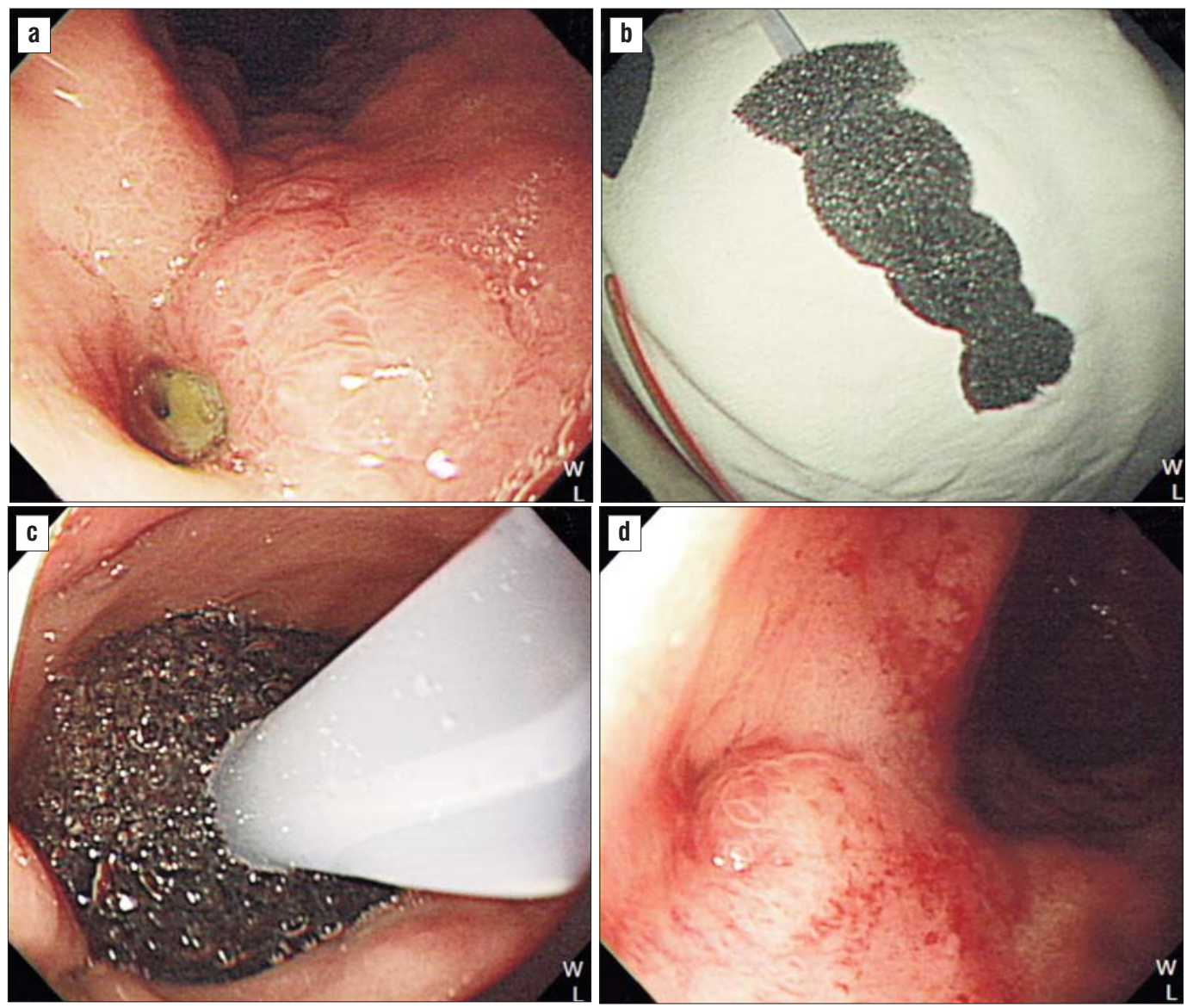

Figure 1 - Endoscopic imaging of vacuum-assisted closure with open-pore polyurethane foam. (a) A wall defect in the intrathoracic stomach; (b) The individually adapted polyurethane sponge to the size of the defect and fixation to the tip of the nasogastric tube; (c) Sponge positioning in the intraluminal cavity by grasper forcep under direct view using an endoscope; (d) Complete healing of the wall defect at $\mathbf{4 3}$ days after the procedure

\section{DISCUSSION}

Upper gastrointestinal perforation or postoperative anastomotic leak after esophagectomy or gastrectomy goes incompany with a high rate of morbidity and mortality (14). Physically, after esophageal leaks appear, fluid is aspirated into the mediastinum in a breathdependent manner, creating a complete condition for bacterial growth and by destiny causing fatal mediastinitis.

For a long time, there have been three options such as stent or OTSC as a primary endoscopic treatment or operative revision for esophageal leakage or perforation $(8,15,16)$. In most cases, re-suture of anastomotic site is almost impossible, and after esophageal resection, the patient may eventually ends up having a persistent fistula.

Placement of covered stent in patients with esophageal perforation or leak can reduce the morbidity of intervention and may be a secure and viable alternative to surgical therapy (17). However, from time to time there may be difficulties with stent placement, positioning, migration and removal. If the stent is placed to prevent leakage, bacteria will remain and multiply rapidly in the mediastinum. Generally, sepsis will continue because the formed mediastinal abscess is not drained. Thus, antibiotic therapy and further drainage through the chest tube may be essential.

Lately, a new measure called endoscopic vacuum treatment has been introduced as an alternative to upper gastrointestinal leakage or perforation. This highly promising pilot method can purify the infectious source by inserting a sponge into the site of the esophageal wall defect and washing the lesion. Under the periodic observation of the lesion, adequate continuous suction and best drainage supplied with the open-pored sponge and vacuum system decrease local edema, secretion, and source bacterial contamination. 


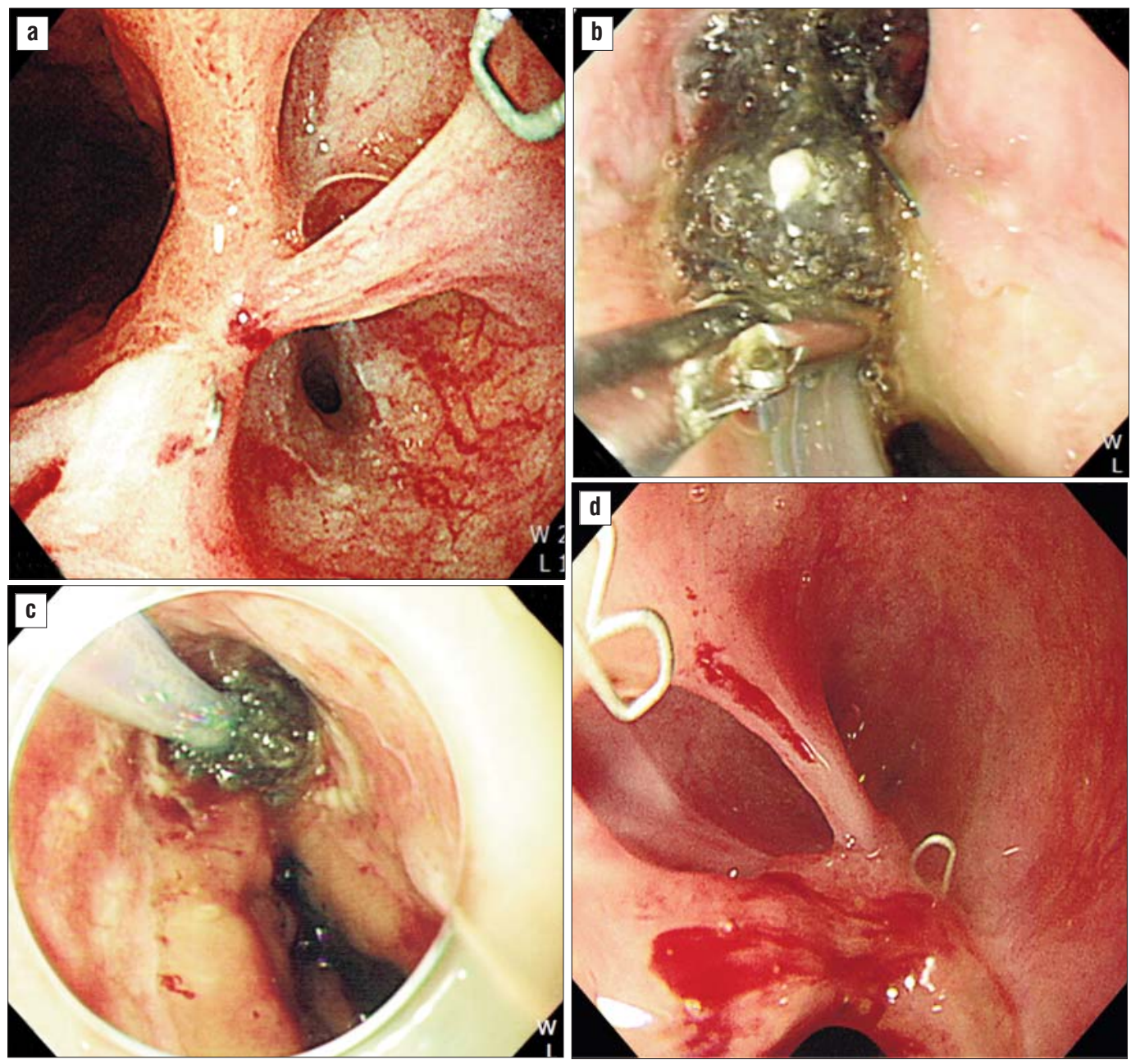

Figure 2 - Endoscopic imaging of vacuum-assisted closure with open-pore polyurethane foam. (a) A wall defect in the anastomotic site; (b) Using grasper forceps, the nasogastric tube was inserted; (c) Sponge positioning in the intraluminal cavity under direct view using an endoscope; (d) Complete healing of the wall defect at 81 days after the procedure

Simultaneously, rapid tissue granulation, perfusion of the esophageal wall, and the closure of the esophageal defect is promoted. For small defects, a transnasal endoscopy or rinsing (for example, with $50 \mathrm{ml}$ sterile water) is used to determine if there is any wound cavity outside the lumen. If this is not the case, inserting a polyurethane foam drain tube into the lumen is a preferred method. If there is a larger size leak with a wound cavity, it is a favored procedure to insert the drain tube into the cavity.

Previous studies reporting heterogeneous types of upper GI tract leakages reported comparable success rates without procedure-related complications $(18-21)$. The success rate for anastomotic leakage was $90 \%$, and the success rate for esophageal perforations was achieved in $96 \%$. The median duration of therapy took 17 days (22). Further comparative retrospective studies demonstrated that EVT is superior to surgical revision and stent placement in managing major esophageal leaks, especially in septic patients $(11,23,24)$. Brangewitz et al. compared the outcome of 32 patients after EVT and 39 patients after stent insertion in a retrospective analysis (9). The overall closure rate of leakages was significantly higher in the EVT group than in the stent group (84.4\% vs. $53.8 \%$ ). Additionally, they found significantly more strictures in the stent group (28.2 vs. $9.4 \%$ ). The success of EVT is reflected by the size of the extramural cavity, accumulation of secretion, and formation of granulation tissue.

In contrast, the need for repetitive endoscopic procedures, long therapy duration, patient discomfort, and inevitable impairment of local perfusion are still disadvantages. Laukoetter et al. strongly recommend EVT for esophageal perforations to be performed 
combined with a CT scan of the thorax done directly before or after every first endoscopic placement of the sponge to exclude close proximity of the sponge to cardiovascular structures with subsequent risk of erosion bleeding. Therefore, the risk factors of EVT still need to be monitored very closely (25). Especially the risk of hemorrhage by erosion of major vessels due to, e.g., ongoing inflammatory processes needs to be considered just like a pre- or post-interventional sponge position control by computer-tomography is indispensable.

In these advanced and complex cases, surgical procedures to control the wall defects were finally failed due to recurred perforation. The upper gastrointestinal wall defect was managed successfully by combined treatments (endoscopic intraluminal vacuum sponge system and fibrin glue injection) to achieve a shorter duration of treatment and a reduction of E-VAC changes. Anastomotic leakage was successfully treated with 3 5 E-VAC systems over a time period of $43 \sim 81$ days. In accordance with other reports and studies $(11,19,21,24,26)$, the present study reaffirms the role of EVT as a minimally invasive endoscopic option for leaks of the upper gastrointestinal tract with an extraordinary success rate. With regard to this observation, the effects of EVT, i.e., immediate recovery from the sepsis, shortening of recovery period, and complete closure of the leak are most dependent on the size of the defect itself rather than factors such as the severity of sepsis and the cause of the leak. EVT can be used as an isolated or combined therapy with fibrin glue for the acceleration of healing as in this case.

EVT is not only feasible, but safer, and is superior to other methods because it allows direct visualization of wall defects with an endoscope. Thus, EVT can be an appropriate alternative therapy option for esophageal stent insertion, OTSC, or surgical revision in similar situations. We implement EVT as the first gold standard for the treatment of all types of defects or leaks in the gastrointestinal tract to avoid surgical approach, especially in patients with advanced multiple comorbidities.

\section{CONCLUSION}

Our experience supports and adds value to the early promising results of EVT for successful closure of wall defects caused by perforation or anastomotic leakage of the upper gastrointestinal tract. EVT enables the treatment of wall defects in case of patients who are unable to undergo surgery due to multiple coexisting severe illnesses, or in situations where stent insertion is impossible due to serious local infections or extensive esophageal wall defects. Even though there are few prospective studies on the use of EVT in the upper gastrointestinal tract, EVT can already be considered a new life-saving treatment tool.

\section{Conflict of interest}

The authors declare that there is no conflict of interest.

\section{REFERENCES}

1. Miller JD, Jain MK, de Gara CJ, et al. Effect of surgical experience on results of esophagectomy for esophageal carcinoma. J Surg Oncol. 1997;65:20-21.

2. Faller J. Surgery for esophageal and cardia cancer in Hungary: a nationwide retrospective five-year survey. Surg Today. 1996; 26:368-372.

3. Bohm G, Mossdorf A, Klink C, Klinge U, Jansen M, Schumpelick V, Truong S. Treatment algorithm for postoperative upper gastrointestinal fistulas and leaks using combined vicryl plug and fibrin glue. Endoscopy 2010;42:599-602.

4. Hampe J, Schniewind B, Both M, Fritscher-Ravens A. Use of a NOTES closure device for full-thickness suturing of a postoperative anastomotic esophageal leakage. Endoscopy 2010;42:595-598.

5. Tuebergen D, Rijcken E, Mennigen R, Hopkins AM, Senninger N, Bruewer M. Treatment of thoracic esophageal anastomotic leaks and esophageal perforations with endoluminal stents: efficacy and current limitations. J Gastrointest Surg 2008;12:1168-1176.

6. Mennigen R, Senninger N, Laukoetter MG. Novel treatment options for perforations of the upper gastrointestinal tract: endoscopic vacuum therapy and over-the-scope clips. World J Gastroenterol 2014:20:7767-7776.

7. van Boeckel PG, Sijbring A, Vleggaar FP, Siersema PD. Systematic review: temporary stent placement for benign rupture or anastomotic leak of the oesophagus. Aliment Pharmacol Ther 2011;33: 1292-1301.

8. Dasari BV, Neely D, Kennedy A, Spence G, Rice P, Mackle E, Epanomeritakis $E$. The role of esophageal stents in the management of esophageal anastomotic leaks and benign esophageal perforations. Ann Surg 2014;259:852-860.

9. Brangewitz M, Voigtländer T, Helfritz FA, Lankisch TO, Winkler M, Klempnauer J, Manns MP, Schneider AS, Wedemeyer J. Endoscopic closure of esophageal intrathoracic leaks: stent versus endoscopic vacuum-assisted closure, a retrospective analysis. Endoscopy. 2013:45:433-438.

10. Gubler C, Schneider PM, Bauerfeind P. Complex anastomotic leaks following esophageal resections: the new stent over sponge (SOS) approach. Dis Esophagus 2013;26(6):598-602.

11. Schniewind B, Schafmayer C, Voehrs G, Egberts J, von Schoenfels W, Rose T, Kurdow R, Arlt A, Ellrichmann M, Jurgensen C, Schreiber $\mathrm{S}$, Becker T, Hampe J. Endoscopic endoluminal vacuum therapy is superior to other regimens in managing anastomotic leakage after esophagectomy: a comparative retrospective study. Surg Endosc 2013;27:3883-3890.

12. Fleischmann W, Strecker W, Bombelli M, Kinzl L. Vacuum sealing as treatment of soft tissue damage in open fractures. Unfallchirurg 1993;96(9):488-492.

13. Venturi ML, Attinger CE, Mesbahi AN, Hess CL, Graw KS. Mechanisms and clinical applications of the vacuum-assisted closure (VAC) Device: a review. Am J Clin Dermatol 2005;6(3): 185-194.

14. Vallböhmer D, Hölscher AH, Hölscher M, Bludau M, Gutschow C, Stippel $D$ et al. Options in the management of esophageal perforation: analysis over a 12-year period. Dis Esophagus 2010;23(3): 185-190. 
15. Persson S, Elbe P, Rouvelas I, et al. Predictors for failure of stent treatment for benign esophageal perforations - a single center 10year experience. World J Gastroenterol 2014;20(30):10613-10619.

16. Liu SY, Wong SK, Ng EK. Novel oesophago-gastro-duodenal stenting for gastric leaks after laparoscopic sleeve gastrectomy. Obes Res Clin Pract 2015;9(3):214-219.

17. Leers JM, Vivaldi C, Schäfer H, Bludau M, Brabender J, Lurje G et al. Endoscopic therapy for esophageal perforation or anastomotic leak with a self-expandable metallic stent. Surg Endosc 2009;23(10): 2258-2262.

18. Smallwood NR, Fleshman JW, Leeds SG, Burdick JS. The use of endoluminal vacuum (E-Vac) therapy in the management of upper gastrointestinal leaks and perforations. Surg Endosc 2015;30: 2473-2480.

19. Bludau M, Holscher AH, Herbold T, Leers JM, Gutschow C, Fuchs H, Schroder W. Management of upper intestinal leaks using an endoscopic vacuum-assisted closure system (E-VAC). Surg Endosc 2014; 28:896-901.

20. Schorsch T, Muller C, Loske G. Endoscopic vacuum therapy of perforations and anastomotic insufficiency of the esophagus. Chirurg 2014:85:1081-1093.

21. Heits N, Stapel L, Reichert B, Schafmayer C, Schniewind B, Becker
T, Hampe J, Egberts JH. Endoscopic endoluminal vacuum therapy in esophageal perforation. Ann Thorac Surg 2017: 97:1029-1035.

22. Kuehn F, Loske G, Schiffmann L, Gock M, Klar E. Endoscopic vacuum therapy for various defects of the upper gastrointestinal tract. Surg Endosc. 2017;31(9):3449-3458.

23. Mennigen R, Harting C, Lindner K, Vowinkel T, Rijcken E, Palmes D, Senninger N, Laukoetter MG. Comparison of endoscopic vacuum therapy versus stent for anastomotic leak after esophagectomy. J Gastrointest Surg 2015;19:1229-1235.

24. Brangewitz M, Voigtlander T, Helfritz FA, Lankisch TO, Winkler M, Klempnauer J, Manns MP, Schneider AS, Wedemeyer J. Endoscopic closure of esophageal intrathoracic leaks: stent versus endoscopic vacuum-assisted closure, a retrospective analysis. Endoscopy 2013;45:433-438.

25. Laukoetter MG, Mennigen R, Neumann PA, Dhayat S, Horst G, Palmes D, Senninger N, Vowinkel T. Successful closure of defects in the upper gastrointestinal tract by endoscopic vacuum therapy (EVT): a prospective cohort study. Surg Endosc. 2017:31(6): 2687-2696.

26. Schorsch T, Muller C, Loske G. Endoscopic vacuum therapy of anastomotic leakage and iatrogenic perforation in the esophagus. Surg Endosc 2013:27:2040-2045. 